Arch Dermatol Res (1988) 280:308-318

\title{
Pathogenesis of pili annulati
}

\author{
M. Ito ${ }^{1}$, K. Hashimoto ${ }^{2}$, F. Sakamoto ${ }^{1}$, Y. Sato ${ }^{1}$, and J. J. Voorhees ${ }^{3}$ \\ 1 Department of Dermatology, Niigata University School of Medicine, Niigata 951, Japan \\ 2 Department of Dermatology, Wayne State University School of Medicine, Detroit, and Veterans Administration Center, \\ Allen Park, USA \\ ${ }^{3}$ Department of Dermatology, University of Michigan Medical Center, Ann Arbor, Mich., USA
}

Summary. Plucked scalp hairs and hair roots of pili annulati were examined to understand their pathogenesis. Stereoscopic examinations of hairs in transmitted light and/or reflected light and light microscopic surveys of the cross-sections of hairs confirmed that the cortical empty spaces appeared to be responsible to the unique dotted shiny appearance of the hairs seen by the unaided eyes under a refracted light. By transmission electron microscope, small vacuoles and dense bodies were observed in the cytoplasm of the differentiating cortical cells; subsequently, with increasing number of tonofilaments, an uneven distribution of free ribosomes occurred and abnormal spaces containing fine granular substances were formed in the cytoplasm of the cortical cells. Occasionally, extremely large cortical trichohyaline granules were found. In the keratinized hair, irregular empty spaces were present in the cortex of the abnormal hair segments. Histochemically, the keratinized cortex of the affected hairs always had more residual SH groups than the controls. Pili annulati may be a disorder of protein metabolism involving a partial dysfunction of cytoplasmic ribosomes, resulting in a lack of cortical keratin formation.

Key words: Pili annulati - Ultrastructure - DACM staining - Hair cortex - Protein metabolism

Pili annulati is a rare hair anomaly characterized by the unique, dotted shiny appearance of alternating light and dark parts of hair when viewed under a refracted light; the light parts are generally thought to be abnormal and due to air-filled cavities formed in the affected hair [2]. This hair disorder is considered to be inherited, although some sporadic cases have been seen [17]. Most of the cases may show abundant scalp hair and some cases may show a fragility of hair

Offprint requests to: Masaaki Ito, M. D. (address see above) and develop alopecia $[2,10,17]$. Several studies of the affected hair using the scanning electron microscope (SEM) $[3,17]$ and transmission electron microscope (TEM) $[5,13,14]$ have been reported; however, the pathogenesis is still unclear.

Recently, we have studied two siblings affected by pili annulati, one of whom showed a severe fragility of hair. The plucked hairs from both patients were examined ultrastructurally by SEM and TEM and histochemically by N-(7-dimethylamino-3-methyl-4coumarinyl)maleimide (DACM) staining.

\section{Materials and methods \\ Hair samples}

Two Caucasian siblings, a 12-year-old female and an 11-yearold male, affected by pili annulati were seen in the outpatient clinic of the Department of Dermatology, Wayne State University School of Medicine. The scalp hair of the boy was hazel in color, abundant, well grown, slightly curled, and showed the typical feature of pili annulati; when viewed under a regular fluorescent room light, the hair looked normal, while it revealed the unique, dotted, shiny appearance under a refracted light. The hairs of the girl were essentially the same as those of the boy; however, her hair was rather brittle since birth and a severe sparse hair-loss had recently developed. The plucked scalp hair samples were obtained from both cases.

The family history was significant in that the father of both patients had a similar hair abnormality without alopecia.

\section{Stereoscopic examination}

Over 30 hair samples were put onto a glass slide on the object stage in Nikon Multiphoto (Nikon, Tokyo). The hair samples were observed under reflected or transmitted light or under both. As controls, black hairs from two normal Japanese males, white hairs from three Japanese males and two Japanese females with canities, and red or blonde hairs from five Caucasian females, all of which looked normal, were similarly observed.

\section{Procedure for SEM observation}

The patients' hair samples without fixation were placed on brass stages with conductive glue. First, they were observed under 
a stereoscope as described above; their abnormal parts were confirmed and the brass stage surfaces adjacent to the abnormal parts were marked by scratches with a metal needle. Then, the samples were coated with gold, and observed in an SEM (JEM840 ). By the scratch marks on the stage we could easily identify the abnormal parts of the hair in the SEM. Some hairs were transversely cut with a knife under the stereoscope and, then, similarly processed.

\section{Procedures for light microscope and TEM observations}

The abnormal and normal parts, which were confirmed under a stereoscope, and hair roots of the plucked hairs from the patients were separately double-fixed with $5 \%$ glutaraldehyde in $0.1 \mathrm{M}$ cacodylate buffer ( $\mathrm{pH} 7.4$ ) at $4^{\circ} \mathrm{C}$ and $1 \% \mathrm{OsO}_{4}$ in the same buffer immediately after plucking; then they were dehydrated in graded concentrations of alcohol and propylene oxide, and embedded in Epon-812. The thick cross-sections of the segmented hairs and the longitudinal sections of the hair roots were cut at $0.5 \mu \mathrm{m}$ thickness with diamond knives in an ultramicrotome (Sorvall MT-5000), stained with $1 \%$ toluidine blue solution, and observed in a light microscope. After the observation, the ultrathin sections of the embedded hair samples were made with diamond knives in the same ultramicrotome, double-stained with $1 \%$ uranyl acetate and Reynolds' lead citrate [16], and observed in a TEM (JEM-100S). Some of the control hair samples described above were similarly processed and observed.

\section{Procedure of DACM staining}

The patients' hairs and control hairs were embedded side by side in OCT compound (Lab-Tek Division Miles Laboratories, Naperville), frozen at $-30^{\circ} \mathrm{C}$ and simultaneously crosssectioned into $3 \mu \mathrm{m}$ of thickness in a cryostat. This sectioning allowed us to obtain normal control hair sections comparable in thickness and histochemical staining to the hair sections of the patients.

The procedures of DACM staining of these hair sections for SH groups and SS linkages employed were the same as those previously reported [9]. The stained sections were observed in a fluorescence microscope (Standard 18FL, Carl Zeiss, Oberkochen).

\section{Results}

\section{Stereoscopic findings}

At a low power-view in transmitted light, no distinct abnormality was seen in the patients' hairs; their diameters seemed to be uniform throughout the hair (Fig. $1 \mathrm{a}$ ), whereas under reflected light a linear, shiny lightening with irregular widths was seen along the hair (Fig. 1b). When viewed under the combination of reflected and transmitted lights, the shiny patches could be observed more distinctly (Fig. 1c, d, e); the appearance of the hair by the combined light sources most resembled the clinical feature of the patients' individual hairs as observed by the unaided eye. At higher magnifications under transmitted light, peripheral dark patches were localized in the cortex, and central, longitudinal dark bands were seen (Fig. $1 \mathrm{f}, \mathrm{h}$ ). These dark areas were recognized as shiny areas under reflected light (Fig. 1g, i). Control hairs possessed central bands with various widths, lengths, and intervals, but no cortical patches. The white hair from one Japanese person always showed a wide central band continuously throughout the hair shaft (Fig. 1 j, k). The white hairs from the other Japanese person possessed segmented, intermittent, or dotted central bands (Fig. 11, m, n, o). The red or blonde hairs from the Caucasian individuals revealed neither patches nor bands (Fig. 1 p, q), although a few short central bands were found in some hairs from one female. Black hair was unsuitable as a control because of its opacity.

\section{SEM findings}

Although the hair diameters were constant throughout the hair shaft, longitudinal flutes and ridges (Fig. 2a, b) were seen on the surface corresponding to the abnormal parts where the cortical patches were present under reflected light. The stereoscopically normal parts of the patients' hair did not have flutes and ridges, although a slight undulation of the surface was seen (Fig. 2c). The SEM of the cut end of the affected part of the hair showed the presence of small holes in the cortical area and irregularly shaped, large empty spaces in the center of the hair shaft (Fig. 2d). Occasionally, a crescent-like lacuna was found just beneath the hair cuticular layer (Fig. 2d); this lacuna seemed to be an artefact due to the cutting force of the knife, since a similar lacuna was occasionally seen in the similarly processed normal hair.

\section{Light microscopic findings}

Toluidine blue-stain of cross-sections of the affected hair segments showed multiple small empty holes in the cortical area and large empty spaces in the center of the hair (Fig. 3a). Only central empty spaces were found in the cross-section of the hair segment possessing a central band by stereoscopy (Fig. 3 b). Neither empty cortical holes nor central spaces were found in the cross-sections of the hair segments which did not show stereoscopic abnormality (Fig. 3c). In control hairs, the cross-section of the hair with a central band showed central empty spaces (Fig. 3d); no empty space was found in the cross-section of hair without a central band (Fig. $3 \mathrm{e}$ ).

Six anagen hairs having a structurally complete root were obtained. The longitudinal thick sections of the hair roots from the patients showed a normally developing medulla containing medullary granules, although some hair roots lacked medulla. The cortex appeared normal at the lower end of the root. Its 


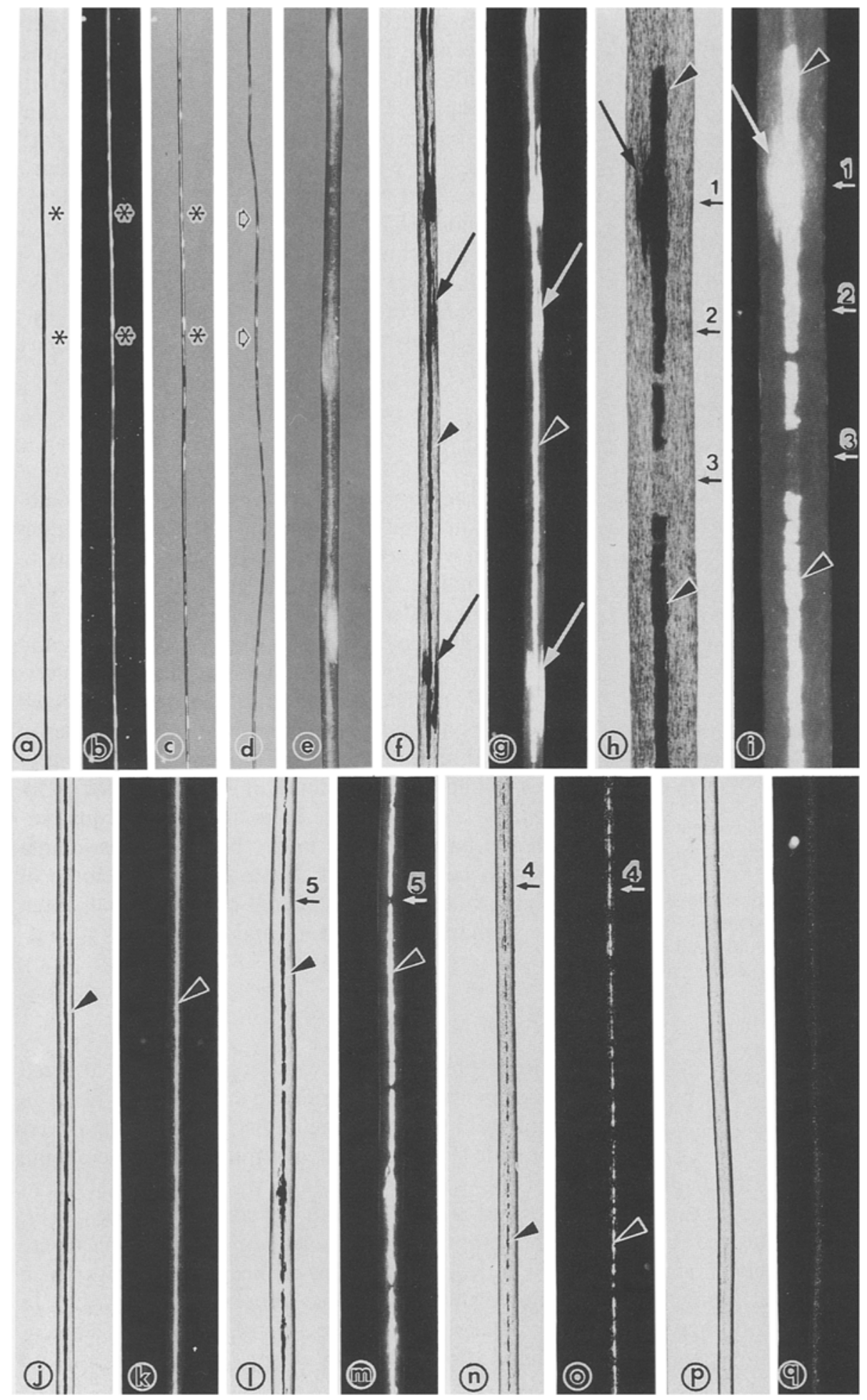

Fig. $1 \mathbf{a}-\mathbf{q}$. Stereoscopic views. a, b, c Hair of pili annulati viewed under transmitted light, reflected light, and the combined lights, respectively. d Hair of pili annulati viewed under the combined lights. e Enlargement of the hair segment indicated by the two small thick arrows in $\mathbf{d}$. The dotted shiny appearance throughout the hair shafts seen in c, d, and e most resembles the clinical appearance of hair. $\mathbf{f}, \mathbf{g}$ Enlargements of the hair segment indicated by the two asterisks in $\mathbf{a}$ and $\mathbf{b}$, respectively. h, i High power-view of hair of pili annulati under transmitted and reflected lights, respectively. Note the cortical patches (long arrows) and central bands (arrowheads), both of which are dark under transmitted light and shiny under reflected light. $\mathbf{j}, \mathbf{k}, \mathbf{l}, \mathbf{m ,} \mathbf{n ,} \mathbf{o}$ Three control white hairs viewed under transmitted or reflected light. These hairs have continuous, segmented, or short central bands (arrowheads). p, q Control blonde hair viewed under transmitted and reflected lights, respectively. Numbered areas in $\mathbf{h}, \mathbf{i}, \mathbf{l}, \mathbf{m}, \mathbf{n}$, and $\mathbf{o}$ will be magnified in Figs. 2 and 3. a, b, $\mathbf{c}, \mathbf{d} \times 5.6 ; \mathbf{e}, \mathbf{f}, \mathbf{g} \times 37 ; \mathbf{h}, \mathbf{i} \times 112$; $\mathbf{j}, \mathbf{k}, \mathbf{l}, \mathbf{m}, \mathbf{n}, \mathbf{o}, \mathbf{p}, \mathbf{q} \times 37$ stainability with toluidine blue gradually became darker upwards. However, during the development of the cortex, longitudinal, spindle-shaped fiber-free areas gradually appeared and increased in number.
Occasionally, a few round small dark granules were present in these fiber-free areas; these granules were similar in size to medullary granules, but they stained darker in color than medullary granules. 


\section{TEM findings}

In the longitudinal sections, the immature hair cortical cells had small cytoplasmic vacuoles; these vacuoles had no limiting membrane, were localized freely in cytoplasm or occasionally in mitochondria, and often contained dense bodies in their centers (Fig, 4a, b). Except for this finding, the immature cortical cells looked normal in ultrastructure (Fig. 4a, b). At the suprabulbar level, with increasing number of tonofilaments, the cytoplasmic vacuoles in the cortical cells gradually increased in number and slightly in size and the cytoplasmic free ribosomes formed aggregations (Fig. 5a, b). The ribosomes were uniformly about $15 \mathrm{~nm}$ in diameter (Fig. $5 \mathrm{~b}$ ). Some of the dense bodies showed a lamellar configuration (inset in Fig. $5 b$ ). The medulla was well developed and produced large round medullary granules up to about $5 \mu \mathrm{m}$ in diameter; in these medulla cells, similar vacuolar changes and aggregations of ribosomes as seen in the cortical cells were present (Fig. 5c, d).

In the keratogenous zone, spindle-shaped fiberfree areas as observed with the light microscope contained uniform fine granular substances instead of tonofilaments (Fig. 6a). The darkly stained cortical granules seen by the light microscope were found to be extremely large cortical trichohyaline granules [6], since these granules had no limiting membrane, were surrounded by ribosomes, and occasionally were in contact with tonofibrils (Fig. 6b). These granules were more electron dense than tonofibrils and degenerating nuclei and less electron-dense than melanosomes. They were $1-3 \mu \mathrm{m}$ in diameter (Fig. 6b).

More distally, the spindle-shaped fiber-free spaces gradually lost their contents and became empty (Fig. 6c). In these empty spaces, in part, irregularly shaped membranous structures gathered and degenerating cell organellae were seen (Fig. 6d). Although a reduced electron density of a few cortical tonofibrils was noticed (Fig. 6c), most tonofibrils seemed normal in ultrastructure.

Thus, the multiple holes in the cortex as observed with the light microscope (Fig. 3a) were found to be intracellular empty spaces in the keratinized cortical cells (Fig. 7a). The sizes of the cross-sections of the cortical cells seemed normal and the keratin fibrils were well organized (Fig. 7a). The hair cuticles covering these abnormal cortexes showed varied degrees of undulation (Fig. 7a). There were some large empty spaces in the center of the hair. The hair segment, in which stereoscopically there was only a central band but no cortical patch (see above), showed normal ultrastructures of hair cortex and cuticule except for the presence of central empty spaces (Fig. 7b); this ultrastructural finding was the same as that (Fig. 8) of the control white hair having a central band on stereoscopic examination.

The light microscope and TEM observations of the control hairs confirmed that the central bands seen with the stereoscope and the central empty spaces in the cross-sections of the affected hairs were medullary spaces.

\section{$D A C M$ findings}

DACM staining for SH groups always displayed significantly stronger diffuse fluorescence in the patient hairs (Fig. 9a, b, c) than in control hairs (Fig. 9a, d), when cross-sections of completely keratinized parts were compared. There was no difference in intensity of the fluorescence by DACM staining for SS linkages between patients' and control hairs (Fig. 9e).

\section{Discussion}

The hair in pili annulati has been known to have airfilled cavities in the hair shaft [2]. The present study confirmed the presence of cavities in the hairs of two patients; the cavities are small holes in the cortex and central large spaces, as has been reported previously $[1,2,11-15]$. However, the present stereoscopic and light microscopic surveys indicate that similar central spaces are present in the control hairs and the histological and ultrastructural surveys show that some hair roots of pili annulati have a well-developed medulla. Therefore, the central spaces in pili annulati may be normal medullary canals similar to those in normal hairs. The cortical holes are found to correlate more with the clinical dotted, shiny appearance of the hair under a refracted light than with the medullary spaces, and the stereoscopic observation of hairs with a combination of transmitted and reflected lights (see Fig. 1c, d, e) seems very helpful to understand this concept. Control white or blonde hairs with intermittent medullary spaces (see Fig. 1 n, o) do not produce such an effect.

In the previous studies using TEM on pili annulati $[13,14]$, the investigators examined only the developed and keratinized hairs. In the present study, no biopsy skin specimen including hair tissues was obtained from the scalp lesion, but only plucked hair roots were obtained; however, several anagen hair roots having a complete structure were included and examined using TEM. The present TEM study suggests that the first morphological change in the hair cells may be the occurrence of small vacuoles and dense bodies in the cytoplasm, although some of the latter may represent regular membrane degenerations. Abnormally large 

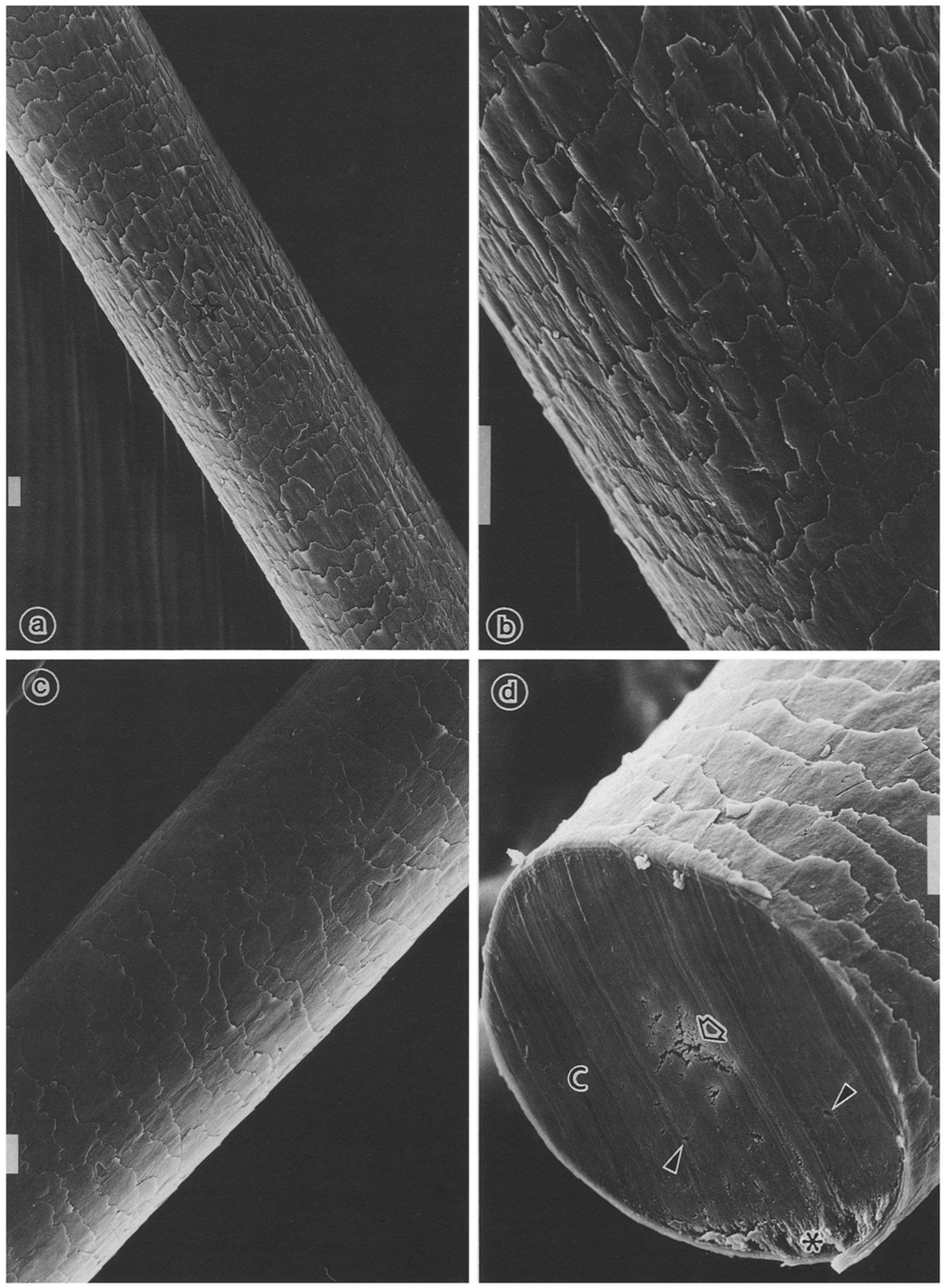

Fig. 2 
aggregations of ribosomes may also contribute to the formation of large holes where they disappear. Similar cytoplasmic vacuoles also appear in the developing medulla cells; however, these seem to be within the normal range of medullary degeneration, although the medullary canals seen in the present cases seem to be well developed (much wider) and more consistently present when compared with those of hairs from normal Caucasians. The presence of extremely large (1 $3 \mu \mathrm{m}$ in diameter) cortical trichohyaline granules may be another sign of abnormal keratinization in the affected hair. In normal developing hair cortical cells, small $(0.1-0.3 \mu \mathrm{m}$ in diameter) round trichohyaline granules appear in even distribution at the level of the keratogenous zone [6].

A biochemical study of hair in pili annulati [3] has indicated that the cystine content was low and its sulfur content normal. In an electron histochemical study of the keratinized hair of pili annulati using the silver methenamine method, Gummer and Dawber have reported the presence of electron-opaque, cystine positive material between the keratin fibrils [5]. These studies seem to suggest that in pili annulati there may be a metabolic abnormality of proteins, especially those rich in cystine or cysteine, in the hair cells. By the present DACM staining, the cortex of the control
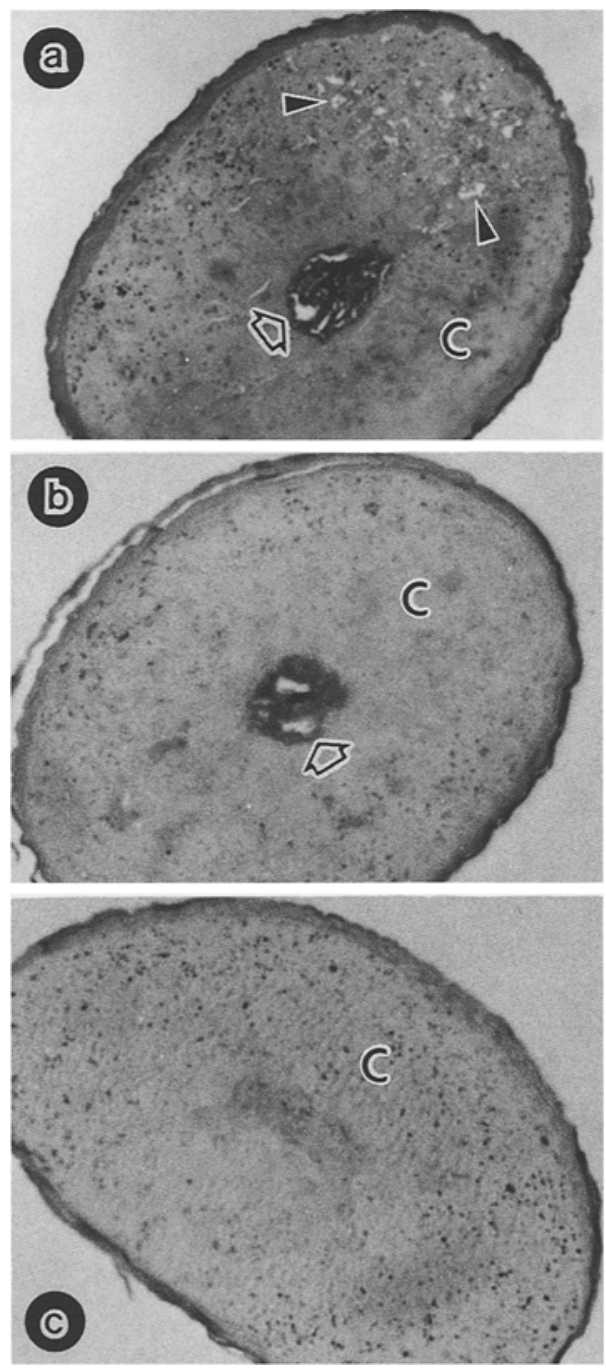
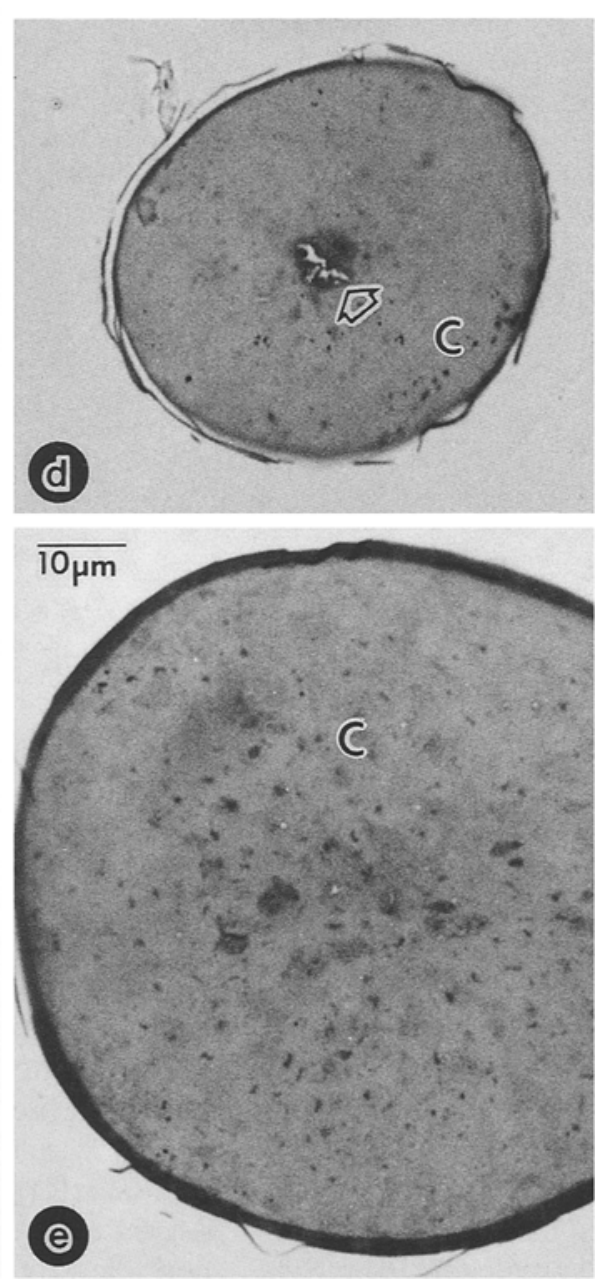

Fig. 3a-e. Light microscopic findings of the hair cross-sections stained with toluidine blue. a, b, c Cross-sections of the pili annulati hair segments similar to those indicated by the small arrows numbered 1, 2 and 3, respectively, in Fig. $1 \mathrm{~h}$ and $\mathrm{i} . \mathrm{d}, \mathrm{e}$ Cross-sections of the control white hair segments similar to those indicated by the small arrows numbered 4 in Fig. $1 \mathrm{n}$ and $o$, and by the small arrows numbered 5 in Fig. 11 and $m$, respectively. Note many empty holes (arrowheads) in the cortex $(C)$ only in a. Thick empty arrow, central empty spaces. a, b, c, d, e $\times 890$

Fig. 2a-d. SEM findings of pili annulati. a SEM photograph of the hair segment similar to that indicated by the small arrows numbered 1 in Fig. $1 \mathrm{~h}$ and i. b Enlargement of the area indicated by star in $\mathbf{a}$. Many longitudinal flutes and ridges of the hair surface are seen over several imbricated cuticle cells. c SEM photograph of the hair segment similar to that indicated by the small arrows numbered 3 in Fig. $1 \mathrm{~h}$ and $\mathrm{i}$. There are no flutes of ridges. $\mathrm{d}$ Cut end of the affected hair. Note small holes (arrowheads) in the cortex (C) and large irregularly shaped space (thick empty arrow) in the center of the hair shaft. Bar, $10 \mu \mathrm{m} . \mathbf{a} \times 500 ; \mathbf{b} \times 1700 ; \mathbf{c} \times 700$; d $\times 1400$ 

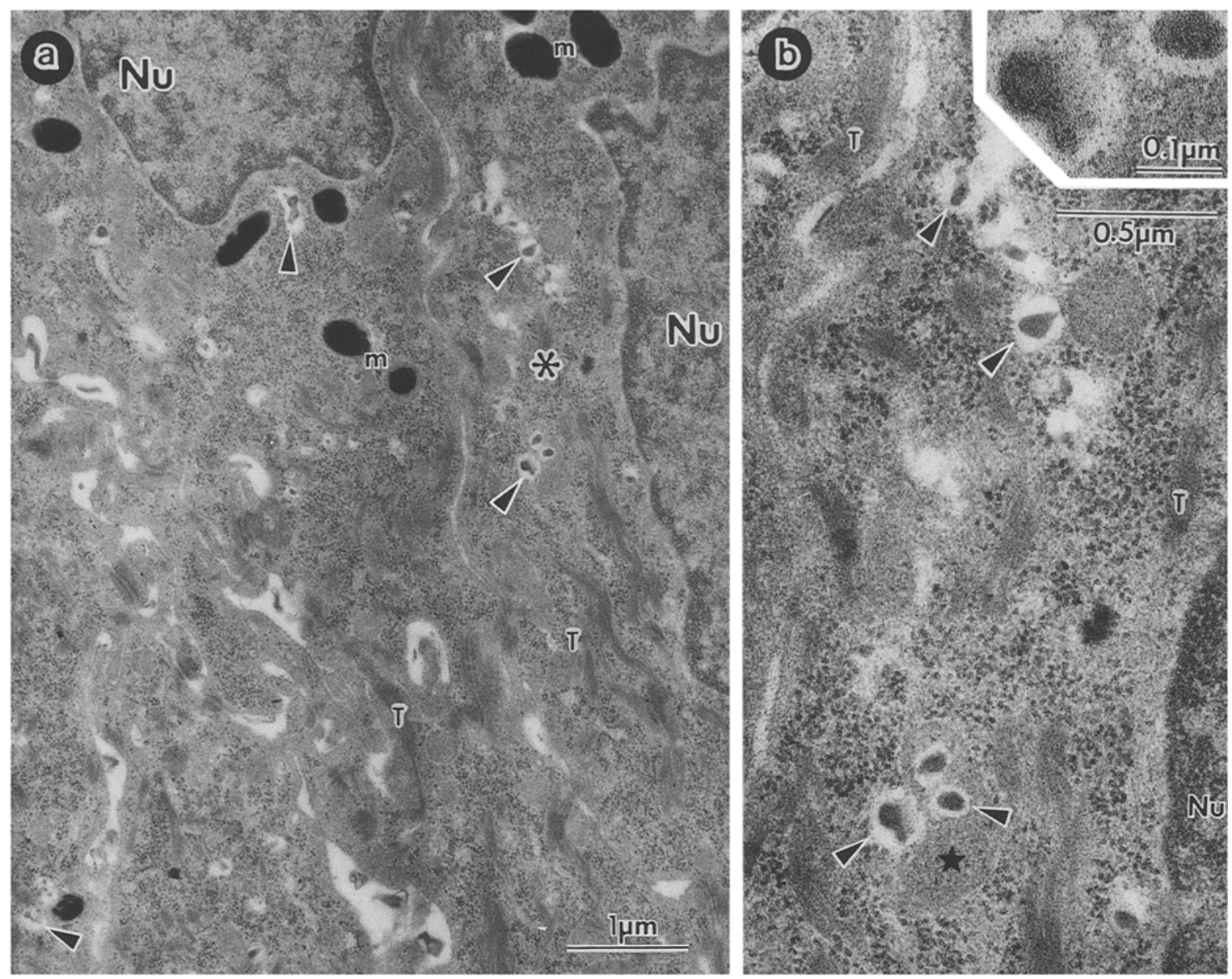

Fig. 4a, b. TEM of the immature hair cortex in pili annulati. a Low-power view. $b$ Enlargement of the area indicated by asterisk in Fig. 4 a. Note the small vacuoles often including dense bodies (arrowheads) in the cytoplasm and in the mitochondrion (star). The dense bodies are enlarged in the inset. $m$, melanosome; $N u$, nucleus; $T$, tonofilaments. Uranyl acetae and lead citrate staining. $\mathbf{a} \times 16000 ; \mathbf{b} \times 40000 ;$ inset in $\mathbf{b} \times 108000$

hair is confirmed to be poor in SH groups $[9,18]$. In contrast, pili annulati hair is always rich in SH groups, suggesting that some of the $\mathrm{SH}$ groups in premature cortical cells fail to be converted to SS linkages in pili annulati, although the intensity of fluorescence demonstrating SS linkages is not significantly different between pili annulati hairs and normal control hairs within a sensitivity of DACM staining. In trichorrhexis invaginata in Netherton's syndrome, SH groups similarly remain in the keratinized hair cortex and this may result from an incomplete conversion from $\mathrm{SH}$ groups to SS linkages in the cytoplasmic proteins during keratinization [9]. Since in pili annulati there is a distribution abnormality of cytoplasmic ribosomes responsible for the production of tonofilament proteins and trichohyaline proteins in the cortical cells, the normal process of $\mathrm{SH}$ to $\mathrm{SS}$ conversion in the keratinizing hair cortex may be incomplete.
The irregularity of the hair surface is found in the abnormal parts having cortical holes in pili annulati [4]. This was confirmed in the present SEM and TEM correlation study.

In monilethrix, longitudinal flutes and ridges in severer degrees have been found on the hair surface at the internodal portions $[4,7,8]$; this change of hair surface with a remarkable reduction of hair diameter in monilethrix is considered to be due to a periodical decrease in number of cortical cells caused by a periodical dysfunction of the hair matrix [8]. However, in pili annulati, there is no gross reduction of hair diameter and only the hair surface irregularity is present at the abnormal parts as shown in the present study. In the normal hair, when cortical cells undergo keratinization, the diameters of the cortex are generally reduced. If some empty or soft spots without solid filaments are formed within the cortex, a slight 

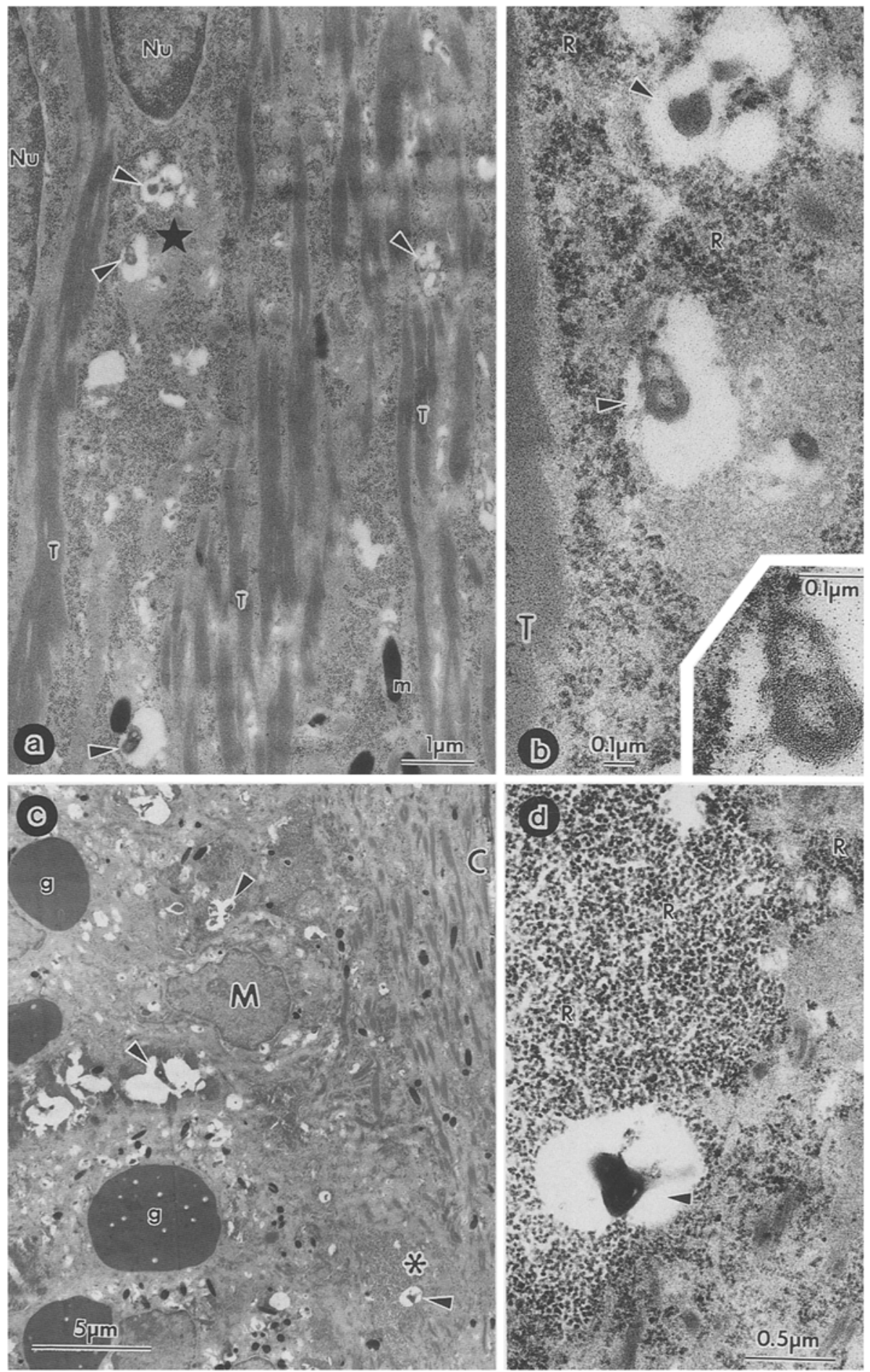

Fig. 5a-d. TEM of the developing hair cells in pili annulati. a Cortex. b Enlargement of the area indicated by star in Fig. 5 a. $\mathbf{c}$ Medulla. d Enlargement of the area indicated by asterisk in Fig. 5c. Note the vacuolar changes sometimes containing dense bodies (arrowheads). One dense body is enlarged in the inset in Fig. 5b and appears to be lamellar. Aggregations of cytoplasmic ribosomes $(R)$ are seen. $C$, cortical cell; $g$, medullary granule; $m$, melanosome; $M$, medulla cell; $T$, tonofilaments. Uranyl acetate and lead citrate staining. a $\times 10500 ; \mathbf{b} \times 42000$; inset in b $\times 90720 ; \mathbf{c} \times 3360 ; \mathbf{d} \times 25200$ 


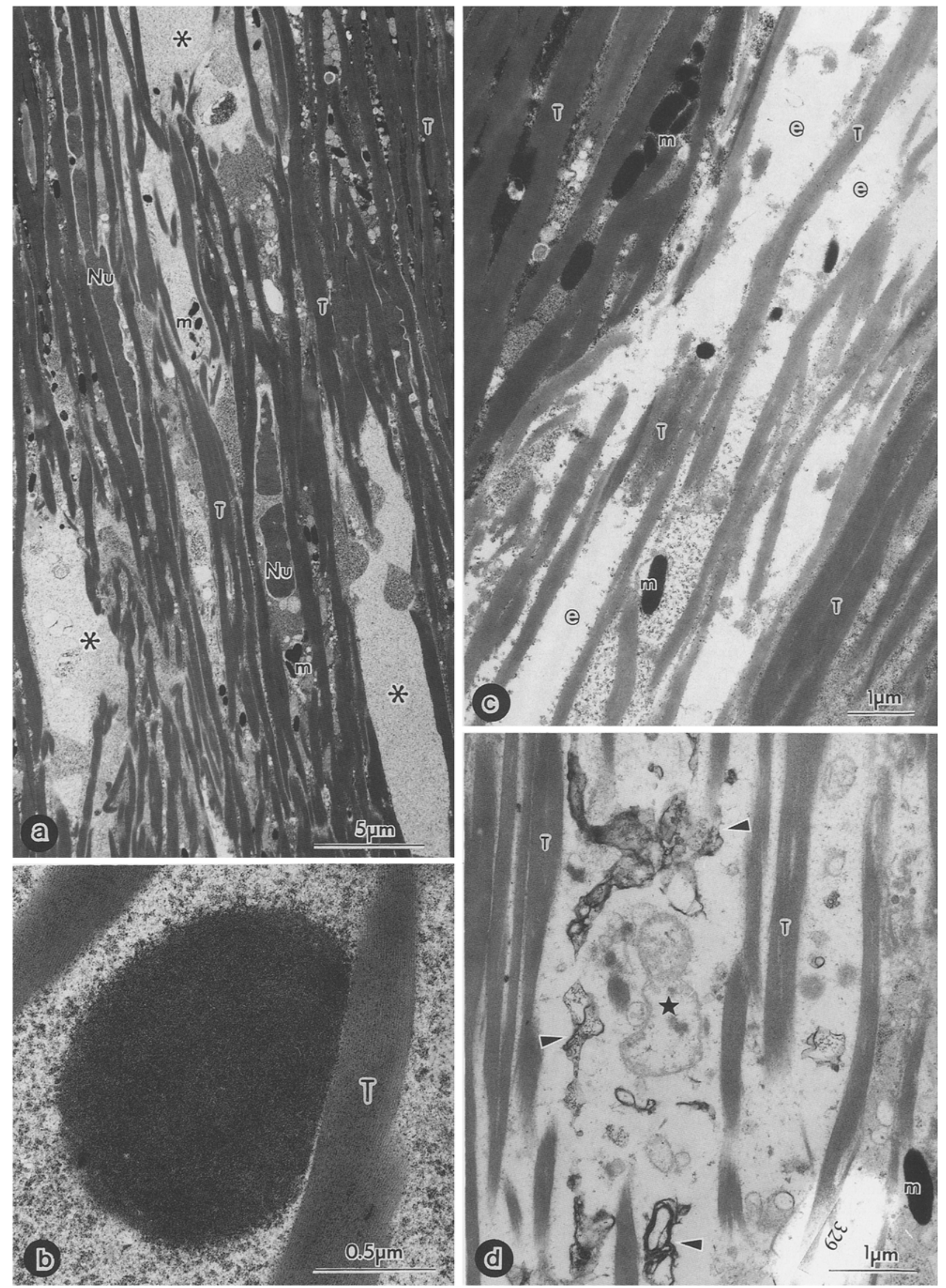

Fig. 6 

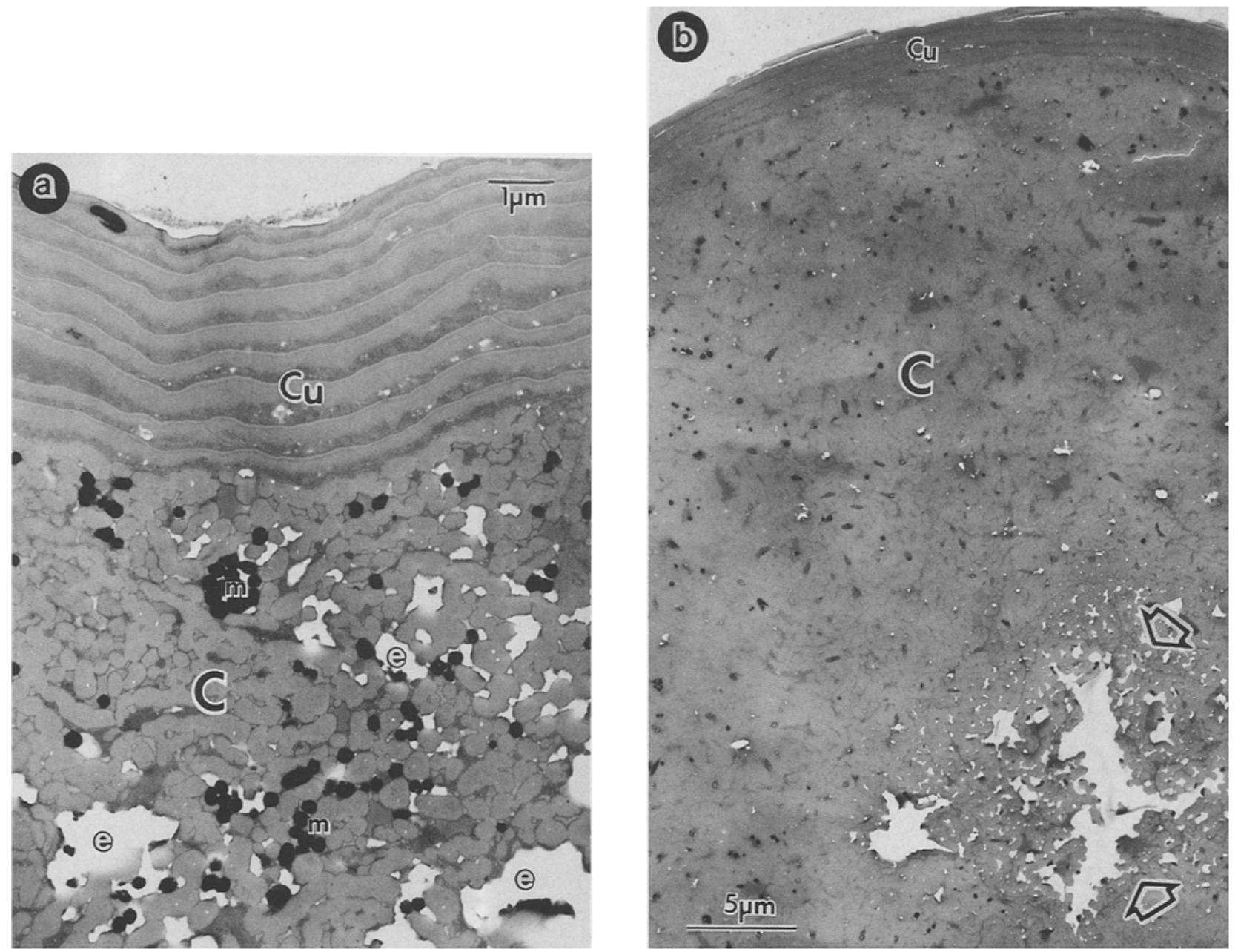

Fig. 7a, b. TEM of hair cross-sections in pili annulati. a TEM of a hair section corresponding to that in Fig. 3 a. Note that many empty holes (e) are present in the cortex $(C)$ and that the hair cuticle $(C u)$ shows an undulation. $b$ TEM photograph of a hair section corresponding to that in Fig. $3 \mathrm{~b}$. The cortex $(\mathrm{C})$ and cuticle $(\mathrm{Cu})$ look normal. Empty large arrow, central empty spaces; $m$, melanosome. Uranyl acetate and lead citrate staining. $\mathbf{a} \times 9000 ; \mathbf{b} \times 3000$

undulation of the hair surface, i.e., cuticule, is expected, although no excessive reduction of hair diameter may occur.

The hair samples from both patients reported here showed similar results, although one patient had normally growing hair and another showed a remarkable loss of hair. Since the present surveys were limited to plucked hairs and no skin biopsy was carried out, it seems probable that in the latter case we have examined only relatively healthy hair and hair roots. How- ever, it is clear that there has been a pathological condition of hair tissues common to both the cases.

It is concluded that pili annulati may be a protein metabolic disorder involving a partial dysfunction of cytoplasmic ribosomes, resulting in a lack of cortical keratin formation. What causes the ribosome aggregation and vacuolar change in the cortical cells remains unknown. Biochemical and biological analyses of hair cells in pili annulati are under further investigation.

Fig. 6a-d. TEM of the hair cortex in keratogenous zone in pili annulati. a Level where the nuclei $(\mathrm{Nu})$ of cortical cells are degenerating. Note that spindle-shaped areas (asterisks) contain fine granular substances between the thick tonofibrils $(T)$. b Large cortical trichohyaline granule. $\mathbf{c}, \mathbf{d}$ Slightly distal level. Empty spaces $(e)$ are gradually formed between tonofibrils $(T)$. Some irregularly shaped membrane structures (arrowheads) and degenerated cell organellae such as mitochondrion (star) are seen in the empty space. $m$, melanosome. Uranyl acetate and lead citrate staining. $\mathbf{a} \times 4000 ; \mathbf{b} \times 45000 ; \mathbf{c} \times 12000 ; \mathbf{d} \times 16000$ 


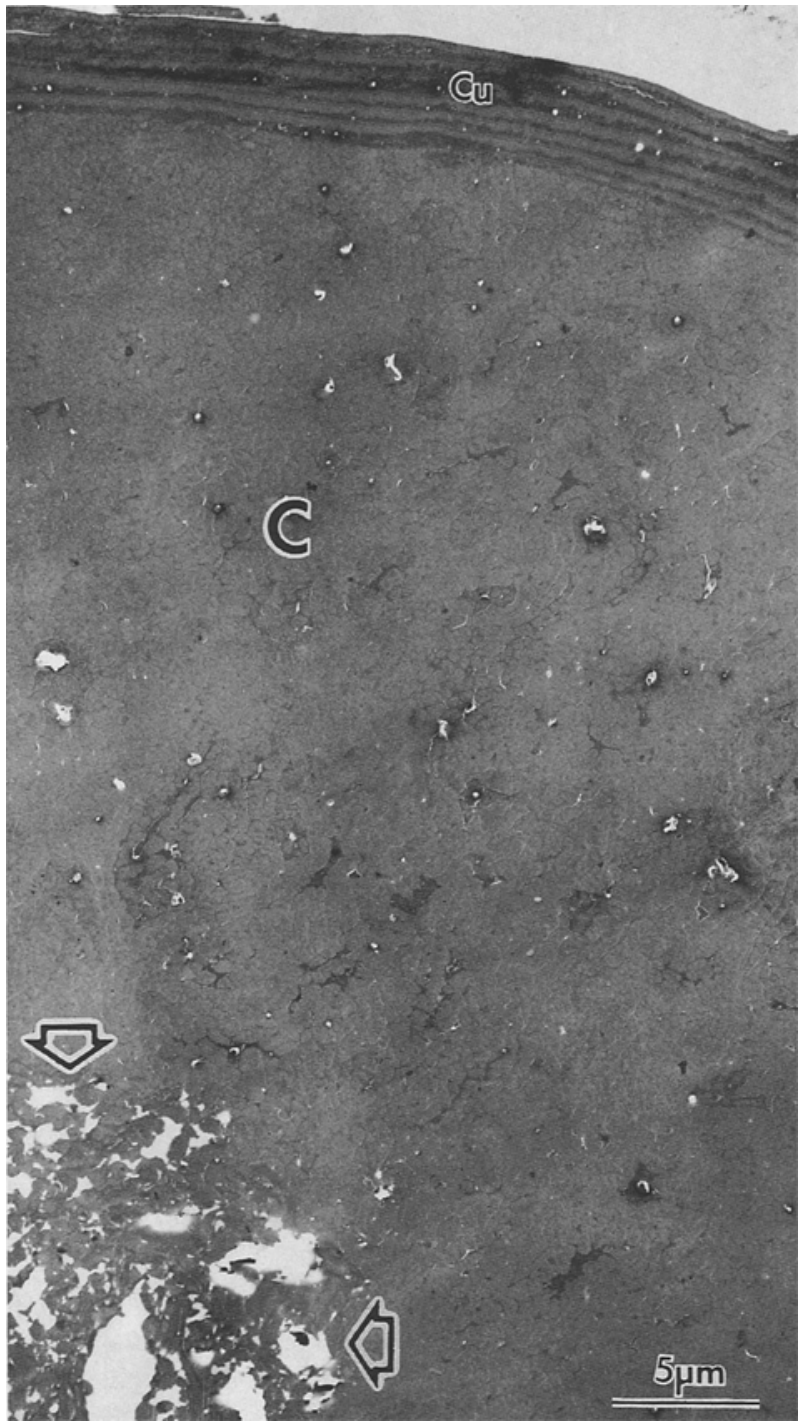

Fig. 8. TEM of cross-section of control white hair corresponding to that in Fig. 3 d. Central empty spaces (empty large arrows) are seen. $C$, cortex; $C u$, cuticle. Uranyl acetate and lead citrate staining. $\times 3000$

\section{References}

1. Ashley LM, Jacoues RS (1950) Four generations of ringed hair. J Hered $41: 82-84$

2. Cady LD, Trotter M (1922) A study of ringed hair. Arch Dermatol Syphilol 6:301-317

3. Dawber RPR (1972) Investigations of a family with pili annulati associated with blue naevi. Trans St John's Hospital Dermatol Soc 58:51-58

4. Dawber R, Comaish S (1970) Scanning electron microscopy of normal and abnormal hair shafts. Arch Dermatol $101: 316-322$

5. Gummer CL, Dawber RPR (1981) Pili annulati, electron histochemical studies on affected hairs. $\mathrm{Br} \mathrm{J}$ Dermatol $105: 303-309$
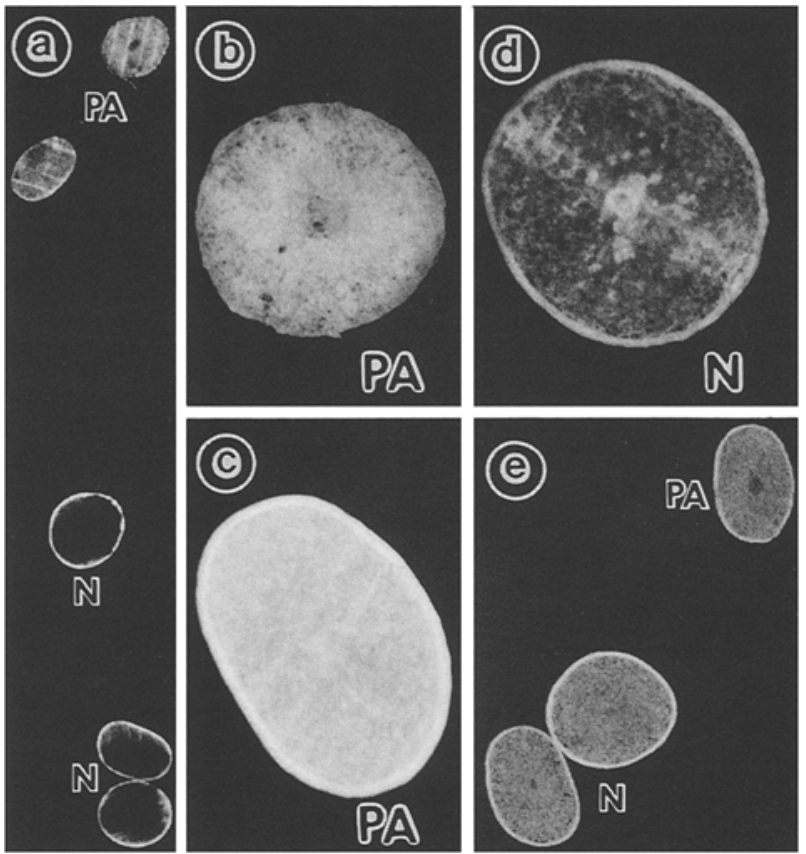

Fig. 9a - e. DACM findings of hair cross-sections. a, b, c, d SH staining. e SS staining. $N$, normal control hair; $P A$, pili annulati hair. a $\times 93$; b, c, d $\times 372 ; \mathbf{e} \times 93$

6. Ito M, Hashimoto K (1982) Trichohyaline granules in hair cortex. J Invest Dermatol 79:392-398

7. Ito M, Hashimoto K (1985) The hair abnormalities. In: Johannessen JV, Hashimoto K (eds) Electron microscopy in human medicine, vol 11(a). The skin. McGraw-Hill, New York, pp 227-273

8. Ito M, Hashimoto K, Yorder FW (1984) Monilethrix, an ultrastructural study. J Cutan Pathol 11:513-521

9. Ito $\mathrm{M}$, Ito $\mathrm{K}$, Hashimoto $\mathrm{K}$ (1984) Pathogenesis in trichorrhexis invaginata (bamboo hair). J Invest Dermatol $83: 1-6$

10. Leider M (1950) Multiple simultaneous anomalies of the hair. Arch Dermatol Syphilol 62:510-514

11. McCleary JE, Montgomery H (1955) Ringed hair. Arch Dermatol 71:526-527

12. Montgomery RM, Binder AI (1948) Ringed hair. Arch Dermatol Syphilol 58:177-179

13. Musso LA (1970) Pili annulati. Aust J Dermatol 11:67-75

14. Price VH, Thomas RS, Jones FT (1968) Pili annulati, optimal and electron microscopic studies. Arch Dermatol 98:640-647

15. Reyn A (1934) Pili annulati occurring as a family disorder. Br J Dermatol Syph 46:168 - 175

16. Reynolds ES (1963) The use of lead citrate at high $\mathrm{pH}$ as an electron-opaque stain in electron microscopy. J Cell Biol $17: 208-212$

17. Rook A, Dawber R (1982) Disease of the hair and scalp. Blackwell, Oxford, pp 208-212

18. Taneda A, Ogawa H, Hashimoto K (1980) The histochemical demonstration of protein-bound sulfhydryl groups and disulfide bonds in human hair by a new staining method (DACM staining). J Invest Dermatol 75:365-369

Received October 22, 1987 